\begin{tabular}{|c|c|c|c|c|c|}
\hline$G$ & $=$ function defined by Eq. (9) or Eq. (12) & {$[-]$} & $v_{w}$ & $=$ radial velocity at wall & {$[\mathrm{m} / \mathrm{sec}]$} \\
\hline$M$ & $=$ axial kinematic momentum flux $=2 \int_{0}^{1} \tilde{u}^{2} \widetilde{r} d \widetilde{r}$ & {$[--]$} & $x$ & $\begin{array}{l}=\text { axial distance from upstream tip } \\
\text { pipe }\end{array}$ & porous $[\mathrm{cm}]$ \\
\hline$\tilde{m}_{w}$ & $=v_{w} / \bar{u}$ & {$[-]$} & $y$ & $=R-r$ & {$[\mathrm{~cm}]$} \\
\hline$p$ & $=$ static pressure & $\left.n \cdot \sec ^{2}\right]$ & & & \\
\hline$R$ & $=$ radius of porous pipe & {$[\mathrm{cm}]$} & $\varepsilon_{M}$ & $=$ eddy diffusivity for momentum & {$\left[\mathrm{cm}^{2} / \mathrm{sec}\right]$} \\
\hline$R^{+}$ & $=R \sqrt{\tau_{w} / \rho} / \nu$ & {$[-]$} & $\rho$ & $=$ density & {$\left[\mathrm{g} / \mathrm{cm}^{3}\right]$} \\
\hline $\operatorname{Re}$ & $=2 \bar{u} R / \nu$ & {$[-]$} & $\tau$ & $=$ shear stress & {$\left[\mathrm{g} / \mathrm{cm} \cdot \mathrm{sec}^{2}\right]$} \\
\hline$r$ & $=$ radial distance & {$[\mathrm{cm}]$} & $\tau_{w}$ & $=$ wall shear stress & {$\left[\mathrm{g} / \mathrm{cm} \cdot \mathrm{sec}^{2}\right]$} \\
\hline$\tilde{r}$ & $=r / R$ & {$[-]$} & $\tau^{+}$ & $=\tau / \tau_{w}$ & {$[-]$} \\
\hline$u$ & $=$ axial velocity & {$[\mathrm{m} / \mathrm{sec}]$} & $\nu$ & $=$ kinematic viscosity & {$\left[\mathrm{cm}^{2} / \mathrm{sec}\right]$} \\
\hline $\bar{u}$ & $=$ average axial velocity & {$[\mathrm{m} / \mathrm{sec}]$} & \multirow{2}{*}{\multicolumn{3}{|c|}{ Literature Cited }} \\
\hline$\tilde{u}$ & $=u / \bar{u}$ & {$[-]$} & & & \\
\hline$\tilde{u}_{\max }$ & $=u_{\max } / \vec{u}$ & {$[-]$} & \multirow[t]{2}{*}{ 1) } & \multirow{2}{*}{\multicolumn{2}{|c|}{$\begin{array}{l}\text { Ito, R., Y. Hirata, J. Ikeda, N. Imamura and K. Sakata: } \\
\text { J. Chem. Eng. Japan, 12, } 91 \text { (1979). }\end{array}$}} \\
\hline$u_{\max }^{+}$ & $=u_{\max } / \sqrt{\tau_{w} / \rho}$ & {$[-]$} & & & \\
\hline
\end{tabular}

\title{
ANALYSIS OF MOMENTUM AND HEAT TRANSFER THROUGH A MOVING INTERFACE WITH FORCED INJECTION AND SUCTION
}

AKIRA HIRATA, KoICHIRo KIRA AND Yoshizo SUZUKI Chemical Engineering Course, Department of Applied Chemistry, Waseda University, Tokyo 160

It is well known that the interfacial velocities, normal and tangential, are very important factors for momentum, heat and mass transfer through a heterogeneous interface. The former is caused by transference of fluid through the interface, and the latter by tangential motion of the interface itself. A number of studies in this field have been reported. However, most of them were studies of the normal ${ }^{2-5,11)}$ or tangential $^{1,9,12)}$ component of interfacial velocity alone. An analysis considering them simultaneously for momentum and heat transfer is presented in this paper.

\section{Fundamental Equations}

Consider a flat plate which is parallel to a constant free stream and moving in the same direction of the free stream with forced injection or suction. Temperature of the interface is constant along the interface, i. e. independent of $x$. For steady laminar flow with negligible dissipation and fluid properties which are independent of temperature, the boundary layer equations of momentum and energy can be written in terms of the similarity transformations.

$$
\begin{aligned}
& 2 f^{\prime \prime \prime}+f f^{\prime \prime}=0 \\
& 2 \theta^{\prime \prime}+\operatorname{Prf} \theta^{\prime}=0
\end{aligned}
$$

Received April 7, 1979. Correspondence concerning this article should be addressed to A. Hirata. K. Kira is now with Kobe Steel. Ltd., Kobe 657.
Boundary conditions are

$$
\begin{array}{r}
f(0)=-2\left(v_{s} / u_{\infty}\right) R e_{x}^{1 / 2}, f^{\prime}(0)=u_{s} / u_{\infty}, \theta(0)=1 \\
f^{\prime}(\infty)=1, \quad \theta(\infty)=0
\end{array}
$$

Where $v_{s}$ is the injection velocity and $u_{s}$ is the velocity of moving interface. We call them respectively "normal and tangential interfacial velocity" hereafter.

It is assumed that normal interfacial velocity $v_{s}$, which is caused by forced injection or suction, varies as $1 / x^{1 / 2}$. Under this assumption, Eqs. (1) and (2) have similar solutions since $f(0)$ is independent of $x^{10)}$. From Eqs. (1) through (4) we get the following fundamental relations for momentum and heat transfer.

$$
\begin{aligned}
\left(C_{f x} / 2\right) R e_{x}^{1 / 2}=f^{\prime \prime}(0) & =F_{1}\left(u_{s} / u_{\infty},\left(v_{s} / u_{\infty}\right) R e_{x}^{1 / 2}\right) \\
N u_{x} / R e_{x}^{1 / 2}=-\theta^{\prime}(0) & =F_{2}\left(u_{s} / u_{\infty},\left(v_{s} / u_{\infty}\right) R e_{x}^{1 / 2}, \operatorname{Pr}\right) \\
& =\frac{1}{\int_{0}^{\infty} \exp \left\{-(\operatorname{Pr} / 2) \int_{0}^{\eta} f d \eta\right\} d \eta}
\end{aligned}
$$

Equation (1) cannot be solved analytically, but is readily solved by transforming a two-point boundary value problem to an initial value problem, i. e. finding the value of $f^{\prime \prime}(0)$. The calculations were made for $u_{s} / u_{\infty}=0.0-1.0, \quad\left(v_{s} / u_{\infty}\right) R e_{x}^{1 / 2}=(-10)-2.0, \quad R r=0.5-$ 5000 . 


\section{Results}

\section{1 The velocity profiles}

The velocity profiles when tangential and normal interfacial velocities are simultaneously considered are shown in Fig. 1. In Fig. $1\left(v_{s} / u_{\infty}\right) R e_{x}^{1 / 2}$, which is called "blowing parameter" according to Hartnett and Eckert ${ }^{5)}$, is 0.6 (injection). When $u_{s}=0$, no tangential interfacial velocity, the velocity boundary layer is lifted away and has an S-shaped velocity profile. However, in the presence of tangential interfacial velocity the velocity boundary layer becomes thinner, as shown in Fig. 1. This effect is also present in the case of suction.

Local skin-friction coefficient given by Eq. (5) is shown in Fig. 2. In the case of suction, $\left(C_{f x} / 2\right) R e_{x}{ }^{1 / 2}$ increases from the value at $v_{s}=0$ (when $u_{s}=0$ it is the well-known Blasius value of 0.332 ) with increasing suction velocity. Over the whole range of suction, larger $u_{s}$ gives smaller $\left(C_{f x} / 2\right) R e_{x}^{1 / 2}$. In the case of injection, $\left(C_{f x} / 2\right) R e_{x}^{1 / 2}$ decreases monotonously with increasing $\left(v_{s} / u_{\infty}\right) R e_{x}^{1 / 2}$. However, the rate of decrease of $\left(C_{f x} / 2\right) R e_{x}^{1 / 2}$ is influenced by $u_{s} / u_{\infty}$. The larger $u_{s} / u_{\infty}$ is, the more slowly $\left(C_{f x} / 2\right) R e_{x}^{1 / 2}$ decreases. The curves for various $u_{s} / u_{\infty}$ in Fig. 2 cross each other in the injection region. Therefore, the condition of $u_{s}=0$ does not give $\left(C_{f x} / 2\right) R e_{x}^{1 / 2}$ maximum value. For example, $u_{s} / u_{\infty}=0.43$ gives maximum value of $\left(C_{f x} / 2\right) R e_{s}^{1 / 2}=0.075$ at $\left(v_{s} / u_{\infty}\right) R e_{x}^{1 / 2}=0.6$.

When $u_{s}=0$, the velocity boundary layer is blown away at $\left(v_{s} / u_{\infty}\right) R e_{x}{ }^{1 / 2}=0.619^{5,6,8)}$. But in the presence of tangential interfacial velocity, it is not blown away at this value of $\left(v_{s} / u_{\infty}\right) R e_{w}^{1 / 2}$, as shown in Fig. 2, since $u_{s}$ thins the velocity boundary layer.

\section{2 Heat transfer coefficient}

Local heat transfer coefficient given by Eq. (6) is shown in Fig. 3 for $P r=0.7 . N u_{x} / R e_{x}^{1 / 2}$ decreases monotonously with increasing $\left(v_{s} / u_{\infty}\right) R e_{x}^{1 / 2}$. Tangential interfacial velocity increases $N u_{x} / R e_{x}{ }^{1 / 2}$ for the whole range of $\left(v_{s} / u_{\infty}\right) R e_{x}^{1 / 2}$. When $P r=1$ the following relation is readily obtained from Eq. (6).

$$
N u_{x} / R e_{x}^{1 / 2}=\left(C_{f x} / 2\right) R e_{x}^{1 / 2} /\left(1-u_{s} / u_{\infty}\right)
$$

At large $\operatorname{Pr}, N u_{x} / R e_{x}{ }^{1 / 2}$ varies widely for a slight change of $\left(v_{s} / u_{\infty}\right) R e_{x}^{1 / 2}$. The thermal boundary layer becomes much thinner compared with the velocity boundary layer at sufficiently large $P r$. Therefore, the slight change of velocity profile in the thermal boundary layer caused by injection or suction influences the temperature profile and changes $N u_{x} / R e_{x}{ }^{1 / 2}$ widely. For large $P r$, Kassoy ${ }^{7 /}$ and Thompson ${ }^{13)}$ gave numerical solutions in the case of $u_{s}=0$. Our results agreed mostly with their results.

\section{3 The effect of $\boldsymbol{u}_{s}$ on heat transfer}

Generally $u_{s}$ accelerates the heat transfer rate.

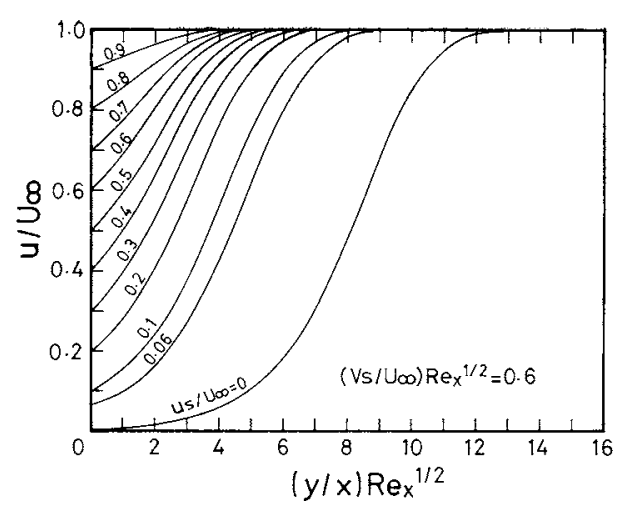

Fig. 1 Velocity profiles in the velocity boundary layer

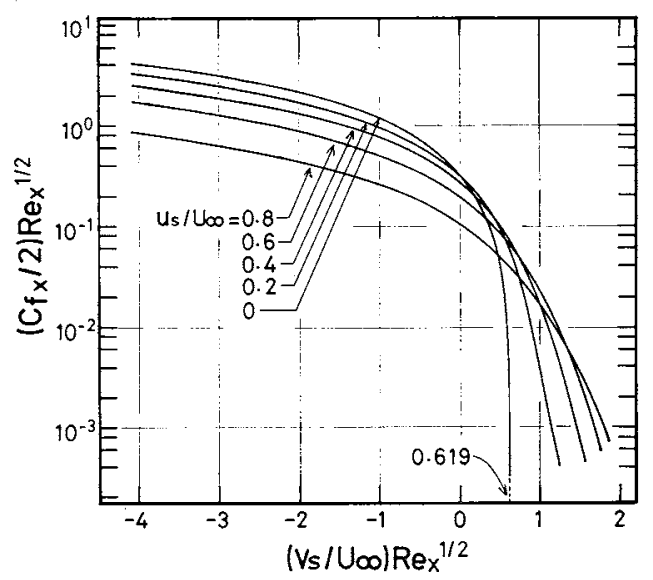

Fig. 2 Local skin-friction coefficient

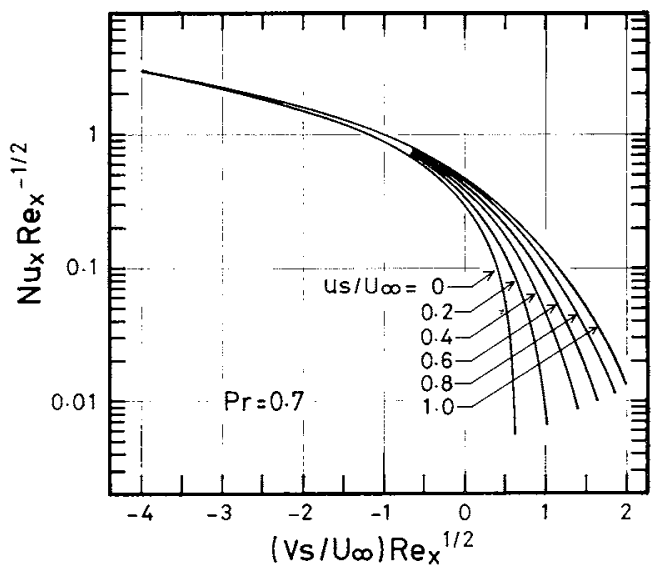

Fig. 3 Local heat transfer coefficient for $P r=0.7$

Figure 3 shows that the effect of $u_{s}$ on $N u_{x}$ is large in injection. On the other hand, it is diminished in suction and at sufficiently large suction $N u_{s}$, is not influened by $u_{s}$. The effect of $u_{s}$ is important in the case of injection. And when $P r$ is sufficiently large, the effect of $u_{s}$ on heat transfer also becomes very impor$\tan t^{12)}$.

\section{4 The effect of $\boldsymbol{P r}$ on heat transfer}

The effect of $P r$ on $N u_{x}$ for $u_{s} / u_{\infty}=0.5$ is shown in 


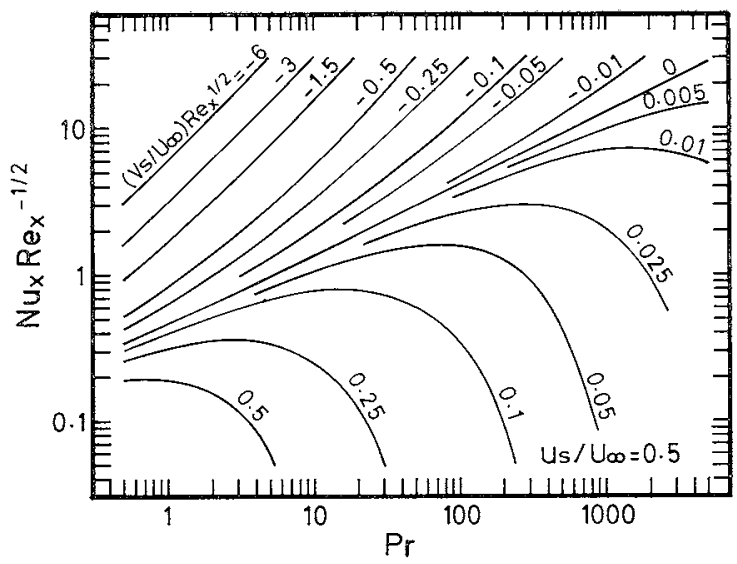

Fig. 4 Effects of $P r$ on heat transfer coefficient for $u_{s} / u_{\infty}=0.5$

Fig. 4. The straight line represents the case of $v_{s}=0$. $N u_{x} / R e_{x}^{1 / 2}$ leaves the straight line of $v_{s}=0$ with increasing $\operatorname{Pr}$ for constant $\left(v_{s} / u_{\infty}\right) R e_{x}^{1 / 2}$. In the case of suction, $N u_{x}$ increases monotonously with $P r$. However, in the case of injection $N u_{s}$ first increases with $\mathrm{Pr}$ and then decreases rapidly with further increase of $P r$, and the thermal boundary layer is blown away. As other values of $u_{x} / u_{\infty}$, this behavior also appeared. However, the line of $v_{s}=0$ is different for every $u_{s} / u_{\infty}$. The effects of $u_{s}$ and $P r$ on heat transfer at $v_{s}=0$ have been detailed in other papers ${ }^{1,12}$.

\section{Approximate Solutions}

\section{1 The case of $u_{s} / u_{\infty}=1$}

Since the velocity boundary layer does not exist, the stream function $f$ can be written as

$$
f=-2\left(v_{s} / u_{\infty}\right) \operatorname{Re}_{x}{ }^{1 / 2}+\eta
$$

Putting Eq. (8) into Eq. (6), we get the following analytical solution:

$$
N u_{x} / \operatorname{Re}_{x}{ }^{1 / 2}=\frac{(\operatorname{Pr} / \pi)^{1 / 2} \exp \left[-\operatorname{Pr}\left\{\left(v_{s} / u_{\infty}\right) \operatorname{Re} e_{x}^{1 / 2}\right\}^{2}\right]}{1+\operatorname{erf}\left\{\operatorname{Pr}^{1 / 2}\left(v_{s} / u_{\infty}\right) \operatorname{Re}_{x} e^{1 / 2}\right\}}
$$

Equation (9) and numerical solutions were in good agreement.

\section{2 The case of $P r \rightarrow 0$}

As $P r \rightarrow 0$, the thermal boundary layer becomes much thicker than the velocity boundary layer. Therefore, $f$ can be also represented approximately by Eq. (8), and it gives the approximate solution Eq. (9). At small $P r$, the effect of $u_{s}$ on heat transfer is diminished and the solutions converge to the analytical solution of $u_{s} / u_{\infty}=1$.

\section{3 The case of $\boldsymbol{P r} \rightarrow \infty$}

The thermal boundary layer becomes much thinner than the velocity boundary layer. $f$ can be represented as

$$
f=-2\left(v_{s} / u_{\infty}\right) \operatorname{Re}_{x}{ }^{1 / 2}+\left(u_{s} / u_{\infty}\right) \eta
$$

and the solution is

$$
\begin{aligned}
& -\frac{N u_{x}}{R e_{x}{ }^{1 / 2}} \\
& =\left(\frac{\operatorname{Pr} u_{s}}{\pi u_{\infty}}\right)^{1 / 2} \frac{\exp \left[-\operatorname{Pr}\left\{\left(v_{s} / u_{\infty}\right) \operatorname{Re}_{x}{ }^{1 / 2}\right\}^{2} /\left(u_{s} / u_{\infty}\right)\right]}{1+\operatorname{erf}\left\{\operatorname{Pr}^{1 / 2}\left(v_{s} / u_{\infty}\right) \operatorname{Re}_{x}{ }^{1 / 2} /\left(u_{s} / u_{\infty}\right)^{1 / 2}\right\}}
\end{aligned}
$$

Equation (11) can be also adapted to the case of large suction.

Equation (11) and numerical solutions at large $P r$, 1000 to 5000 , were in good agreement.

\section{Conclusions}

Momentum and heat transfer were analyzed by considering tangential and normal interfacial velocities simultaneously, and the following information was obtained.

1) $C_{f x}$ and $N u_{x}$ decrease with $\left(v_{s} / u_{\infty}\right) R e_{x}^{1 / 2}$ when $u_{s} \neq 0$.

2) Condition of $u_{s}=0$ does not give maximum friction in the injection region.

3) $u_{s}$ increases the heat transfer rate over the whole range of $\left(v_{s} / u_{\infty}\right) R e_{x}^{1 / 2}$, and its effect is important in the injection region.

\section{Acknowledgment}

This research was supported in part by a grant from the Annual Project Organized by Waseda University in 1975 and 1976.

\section{Nomenclature}

$C_{f, x} \quad=$ local skin-friction coefficient,

$\tau_{s} /(1 / 2) \rho u_{\infty}{ }^{2}$

$f \quad=$ dimensionless stream function $\quad[-]$

$F_{1}, F_{2} \quad=$ function defined by Eqs. (5) and (6) [-]

$h \quad=$ heat transfer coefficient $\quad\left[\mathrm{W} / \mathrm{m}^{2} \cdot \mathrm{K}\right]$

$N u_{x} \quad=$ local Nusselt number, $h x / \hbar$

$\operatorname{Pr} \quad=$ Prandtl number, $\nu / \alpha \quad[-]$

$\operatorname{Re}_{x} \quad=$ local Reynolds number, $u_{\infty} x / \nu$

$T \quad=$ temperature $\quad[\mathrm{K}]$

$u, v \quad=$ velocity parallel to, and normal to the interface $[\mathrm{m} / \mathrm{sec}]$

$x, y=$ coordinate parallel to, and normal to the interface [m]

$\alpha \quad=$ thermal diffusivity $\quad\left[\mathrm{m}^{2} / \mathrm{sec}\right]$

$\eta \quad=(y / x)\left(u_{\infty} x / \nu\right)^{1 / 2}$

$\theta \quad=\left(T-T_{\infty}\right) /\left(T_{s}-T_{\infty}\right) \quad[-]$

$\kappa \quad=$ thermal conductivity $\quad[\mathrm{W} / \mathrm{m} \cdot \mathrm{K}]$

$\nu \quad=$ kinematic viscosity $\left[\mathrm{m}^{2} / \mathrm{sec}\right]$

$\rho \quad=$ density $\quad\left[\mathrm{kg} / \mathrm{m}^{3}\right]$

$\tau \quad=$ shear stress $\quad[\mathrm{Pa}]$

〈Subscripts〉

$\mathrm{s} \quad=$ interface conditions

$\infty \quad=$ free stream conditions

\section{Literature Cited}

1) Acrivos, A.: Chem. Eng. Sci., 9, 242 (1958).

2) Emmons, H. W. and D. C. Leigh: Aero. Res. Counc., CP 157 (1954).

3) Evans, H. L.: Int. J. Heat Mass Transfer, 3, 321 (1961).

4) Gupta, D. S. and A. S. Gupta: Can. J. Chem. Eng., 55, 744 (1977). 
5) Hartnett, J. P. and E. R. G. Eckert: Trans. ASME, Ser. C, 79, 247 (1957).

6) Honma, H. and M. Yajima: Trans. Japan Soc. Mech. Engrs, 43, 3835 (1977).

7) Kassoy, D. R.: AIAA J., 6, 1796 (1968).

8) Klemp, J. B. and A. Acrivos: J. Fluid Mech., 51, 337 (1972).

9) Robillard, L.: Trans. ASME Ser. E, 38, 550 (1971).

10) Schlichting, H.: "Boundary Layer Theory", 6th ed.,
McGraw-Hill, New York (1966).

11) Schlichting, H.: Trans. ASME Ser. E, 38, 289 (1971).

12) Shirotsuka, T., A. Hirata and K. Sakai: Kagaku Kögaku, 33, 168 (1969).

13) Thompson, E. R.: AIAA J., 7, 547 (1969).

(Presented at the 12th Autumn Meeting of The Soc. of Chem. Engrs., Japan, at Okayama, 1978.)

\title{
WAVE INCEPTION ON FALLING LIQUID FILM
}

\author{
RYUZO ITO AND KAORU TOMURA \\ Department of Chemical Engineering, Osaka University, Toyonaka 560
}

Falling liquid films on inclined plates and on vertical walls have many applications to heat and mass transfer equipment. These transfer rates are greatly influenced by the surface behavior of falling liquid films. Films on vertical walls have a "calming zone" without wave motion for a short distance below the liquid distributor ${ }^{6-8-11}$. On the other hand, the present authors ${ }^{3}$ have pointed out that the length of "calming zone" of films on inclined plates is rather long. The dependence of wave inception on $R e$ and/ or inclination angle has not been investigated systematically. Several experimental studies ${ }^{1,6,8)}$ of vertically falling films have been reported, but no reasonable explanations have yet been made.

Some reports suggested the importance of understanding the mechanism of wave inception, for the problems of mass transfer ${ }^{2,11}$, stability ${ }^{5,9)}$ and characteristics $^{7)}$ of falling liquid films.

In this paper, the positions of wave inception at various liquid Reynolds numbers and inclination angles of the plate have been measured and analyzed on the basis of the integral equation of motion.

The experimental apparatus has been described in detail elsewhere ${ }^{3)}$. Liquid Reynolds number Re ranged from 500 to 10,000 , and the inclination angles of the plate were $9^{\circ}, 33^{\circ}$ and $52^{\circ}$. All runs were carried out under no-air flow conditions.

The characteristics of film surface are as follows:

(1) "Calming zone" exists for a certain distance from the distributor and its length does not vary linearly with liquid flow rate, as shown in Fig. 2.

(2) Below the wave inception, rippling waves progress down the plate and gradually lose their regularity.

(3) When $R e>6000$, turbulent spots occur randomReceived May 7, 1979. Correspondence concerning this article should be addressed to $\mathbf{K}$. Tomura. ly to disturb the surface.

The analytical treatment of the integral equation of motion is utilized to describe the position of wave inception.

The film thickness $h_{c *}$ at wave inception can be calculated from Eq. (21) in the previous paper ${ }^{4}$. In Fig. 1, the values of $h_{c *}$ calculated by using the observed values of $x_{c *}$ are shown in the form of $z_{*}\left(\equiv h_{c *}\right.$ $\left.-h_{\infty * *}\right)$ vs. $R e$, and are correlated by

$$
z_{*}=7.505 \cdot 10^{-24} \cdot R e^{5.807}
$$

where $h_{\infty *}$ is equivalent to $u_{\infty *}$ (Eq. (22)) in the previous paper ${ }^{4}$. The coefficient of correlation is 0.975 . Inversely, $x_{c *}$ can be estimated for the given $R e$ and $\theta$ by using Eq. (1). Examples are shown in Fig. 2 with the observed values for $9^{\circ}$ inclined plate and with the available data $^{6,8,11)}$ for vertical wall. Though the

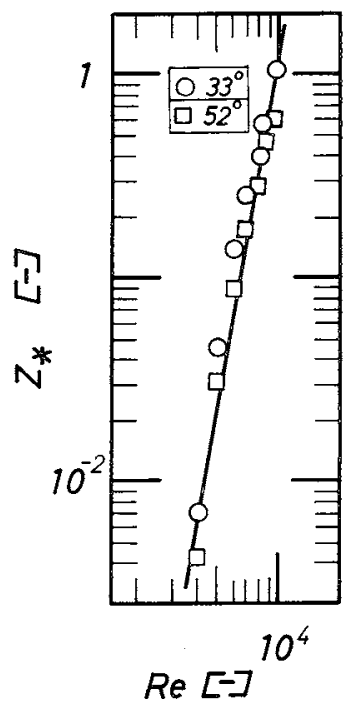

Fig. 1 Film thickness $z_{*}$ at wave inceptino 